\title{
FACTORIES AND THE BLACK-OUT
}

$\mathrm{T}$ HE many problems which have been encountered by those responsible for blacking-out factories in the present emergency were discussed in some detail at a meeting of the Chemical Engineering Group of the Society of Chemical Industry which was held in the rooms of the Chemical Society, Burlington House, I,ondon, on December 8. Mr. H. W. Cremer presided and opened the discussion, during which it was manifested that the actual blacking-out in itself did not produce the only difficulty. It has been found that there are psychological and physiological effects on the workers, to say nothing of difficulties which have been introduced in the matter of ventilation. As regards the latter, tho need for blacking-out factories has rather rovealed that there is yet a great deal to bo learned concerning the ventilation of factories in normal times, and the suggestion that this problem should bo gone into more thoroughly is likely to be taken up by the Committce of the Group.

Mr. Cremer directed special attention to the problem of ventilation and its effect upon night workers, plus the effect of reduced lighting, stressing that factories should be designed normally-and reorganized in present circumstances-with an appreciation of the fact that they have to house human beings as well as machines.

Mr. I. W. Robson, of Messrs. Nobel's Chemical Finishes, Ltd., speaking of the actual physical problems of blacking-out, strongly advocated the extensive use of paint, which he said can be applied rapidly, is cheap and permits of uniform lighting conditions being obtained in the factory by day and by night, so that the efficiency of workers is not affected by changes in degree of illumination prior to and after black-out times. He admitted that the objection to this is a considerable increase in the lighting bill, but claimed that the objection is not so great as is sometimes made out. For example, in the case of buildings camouflaged with paint or netting, the daylight illumination is often reduced to an extent which necessitates artificial. lighting during the daytime. Again, in many engineering shops where fine work is done, bench lights are in constant use, irrespective of daylight or darkness.

Remarking that oil-bound distempers, oil paints and bituminous paints are all suitable for blackingout purposes, Mr. Robson spoke also of the use of aluminium paint for vertical windows, which improves the general brightness of a room by its reflection, but it must not be used on roof lights, as it increases glint.

An alternative to the complete obliteration of windows is the use of complementary lighting, the colours chosen being usually orange and blue. This system is based on well-known optical principles and entails the conversion of the windows to blue filters which will not pass orange light, and the use of lamps which give orange light free from any blue rays. The lamps may be sodium vapour lamps or gas-filled lamps made of suitably coloured glass, or ordinary lamps suitably lacquered. It was empha. sized that photographic workers find no difficulty in working in red or green light of much lower intensity than is afforded by this scheme. (Incidentally, there was some difference of opinion among the speakers on this matter, some referring to trouble with their workers owing to this form of lighting and others saying there had been none, after a short period of time.)

Mention was also made of fluorescent and phos. phorescent paints. Fluorescent paints or pigments, of course, give off visible light when excited by invisible ultra-violet light but have no after-glow when the excitation is removed, whereas phos. phorescent paints continue to glow after the exciting source is removed. The pigments used in these paints are based on zinc and cadmium stlphides. They must be incorporated in a special medium, and the paint, when applied, should be protected with a final coat of clear medium. These paints are obtainable in a variety of colours and glow brilliantly when used with a 'black' lamp.

There aro, of course, numerous applications for such paints under black-out conditions, and it is recommended that where a paint is required for direction indicators in a building which will be suddenly blacked out when a warning is received, it should be of the zinc sulphide type, because of initial brightness. On the other hand, outside signs, or doorways which must be found after many hours of darkness, should be painted with an alkaline earth paint.

Dr. G. E. Foxwell said he had found that vertical retort tar, when heated under certain conditions with lime, had been found excellent for blacking out roof lights and was very resistant to moisture, showing no signs of peeling off. Mr. F. A. Greeno remarked that he had discovered this many years ago, and added that with good quality tar there was no need for treatment with lime.

A number of other points were raised during the course of the discussion, in which some twenty speakers took part, and many of them concerned the extreme difficulty of complying with the regulations and maintaining manufacturing efficiency. For example, there are the numerous cases of large furnaces and the problem of blacking out the glow from them. In one case, where a complete black-out was effected, the men could not continue their work for more than two hours at a time. Some relief was obtained with a system of louvred ventilation combined with a degree of light restriction, but it was extremely costly.

Ono speaker remarked that where a complete black-out had been 100 per cent effective, it was practically 100 per cent defective as regards the workers, who objected to the orange lights and blue windows. The lighting of goods sidings at night has also entailed much difficulty and restriction of operations, but permission has been given by the authorities for a modified form of lighting and an arrangement of switches by which all lights can bo instantly extinguished should a warning be received.

Another difficulty referred to was that of the increaso of temperature in buildings under black-out conditions, due to reduced ventilation in consequence of windows having to be kept closed to prevent emission of light. 